\title{
The Study of Music Education in the Ideological and Political Work in Colleges and Universities under New Situation
}

\author{
Haiyan Wang \\ Kunming University, Kunming, China
}

Keywords: music education; the ideological and political work in colleges and universities, significance

\begin{abstract}
The function of university is talent cultivation, scientific research and service society etc.. It is the cradle of high quality talents to cultivate all-round development. Therefore, the ideological and political education is particularly important in colleges and universities. This paper mainly analyzes the special functions of music education in colleges and universities under the new situation. In addition, this paper discusses the significance of music education in the ideological and political work in colleges and universities under the new situation.
\end{abstract}

\section{Introduction}

The function of the ideological and political education under music education belongs to the cross research category of music education and the ideological and political education. Music education and ideological and political education are the unity of harmony. It is one of the most important parts of the system of ideological and political education. It can enrich the theory of ideological and political education. It provides a new perspective for the development of university ideological and political education work .It's a further subject that reveal the inner relation relationship between the ideological and political education and music education. Under the new era, it has a new connotation.

\section{Research Method}

\subsection{Research Object}

The study subjects are randomly selected. We asked 75 students, which includes 15 students from Music College, 20 art students, 20 students of liberal art and 20 students of sciences, to fill out the questionnaire.

\subsection{Research Method}

We applied anonymous questionnaire survey method. The questionnaire has designed 17 questions from Music education's role in work of the ideological and political education, practical value, challenges and improvement measures ect.. 75 copies of questionnaires were issued, 75 effective questionnaires were recovered and 100\% effective.

\subsection{Findings.}

There are 75 valid questionnaires. The specific situation of science students who fill out the questionnaire is as follows: 8 boys and 12 girls; 12 people from Han nationality and 8 people from other nationalities; seven freshmen, six sophomore, six junior and one senior; 4 people went to music education and others didn't. The specific situation of liberal art students who fill out the questionnaire is as follows: 16 boys and 4 girls; 16 people from Han nationality and 4 people from other nationalities; eleven freshmen, eight sophomore, one junior and no senior; 8 people went to music education and others didn't. The specific situation of art students who fill out the questionnaire is as follows: 11 boys and 9 girls; 16 people from Han nationality and 4 people from other nationalities; nine freshmen, ten sophomore, no junior and one senior; 13 people went to music education and others didn't. The specific situation of music college students who fill out the 
questionnaire is as follows: 3 boys and 12 girls; 12 people from Han nationality and 3 people from other nationalities; one freshmen, ten sophomore, four junior and no senior; 10 people went to music education and others didn't. We have made a list of the above findings: (questionnaire: annex I)

Table 1

\begin{tabular}{|c|c|c|c|c|}
\hline & Gender & Nation & Grand & $\begin{array}{l}\text { Have you taken the } \\
\text { music education class }\end{array}$ \\
\hline \multirow{4}{*}{ Science } & \multirow{2}{*}{$\mathrm{M} / 8$} & \multirow{2}{*}{ Han/12 } & Freshmen/6 & \multirow{2}{*}{ Yes/4 } \\
\hline & & & Sophomore/6 & \\
\hline & \multirow{2}{*}{$\mathrm{W} / 12$} & \multirow{2}{*}{ Others/8 } & junior/1 & \multirow{2}{*}{$\mathrm{No} / 16$} \\
\hline & & & senior $/ 7$ & \\
\hline \multirow{4}{*}{ Liberal Art- } & \multirow{2}{*}{$\mathrm{M} / 16$} & \multirow{2}{*}{ Han/16 } & Freshmen/11 & \multirow{2}{*}{ Yes/8 } \\
\hline & & & Sophomore/8 & \\
\hline & \multirow{2}{*}{ W/4 } & \multirow{2}{*}{ Others/4 } & junior/1 & \multirow{2}{*}{$\mathrm{No} / 12$} \\
\hline & & & senior/0 & \\
\hline \multirow{4}{*}{ Art } & \multirow{2}{*}{$\mathrm{M} / 11$} & \multirow{2}{*}{ Han/16 } & Freshmen/9 & \multirow{2}{*}{ Yes/13 } \\
\hline & & & Sophomore/10 & \\
\hline & \multirow{2}{*}{ W/9 } & \multirow{2}{*}{ Others/4 } & junior/0 & \multirow{2}{*}{$\mathrm{No} / 7$} \\
\hline & & & senior/1 & \\
\hline \multirow{4}{*}{ Iusic Colles } & \multirow{2}{*}{$\mathrm{M} / 3$} & \multirow{2}{*}{ Han/12 } & Freshmen/1 & \multirow{2}{*}{ Yes/10 } \\
\hline & & & Sophomore/10 & \\
\hline & \multirow{2}{*}{ W/12 } & \multirow{2}{*}{ Others $/ 3$} & junior/4 & \multirow{2}{*}{$\mathrm{No} / 5$} \\
\hline & & & senior $/ 0$ & \\
\hline
\end{tabular}

The ratio of men and women in this survey was basically flat. The students from Han nationality are the main investigators, accounting for $75 \%$ of all respondents. Minority students, involved in the Bai, Miao, Hui, Yi, Pumi, Dai, Hani, accounted for $25 \%$ of the respondents. Through the above table we can see, the majority of music students have been attend music education and few of the students in science have taken the music education class.

\section{RELATIONSHIP}
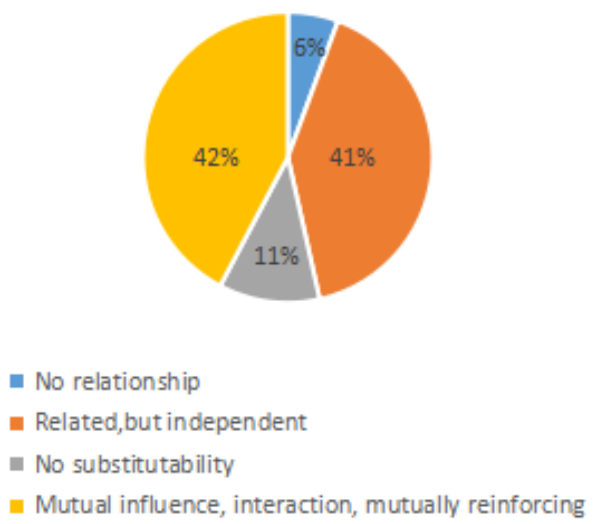

Fig.1

In the survey, four research students thought that music education had no relationship with the ideological and political education. We made a pie chart of the effective investigation. About 83 percent of those surveyed thought the two were independent and complementary. About 6 percent of the participants thought there is no relationship between the two. 


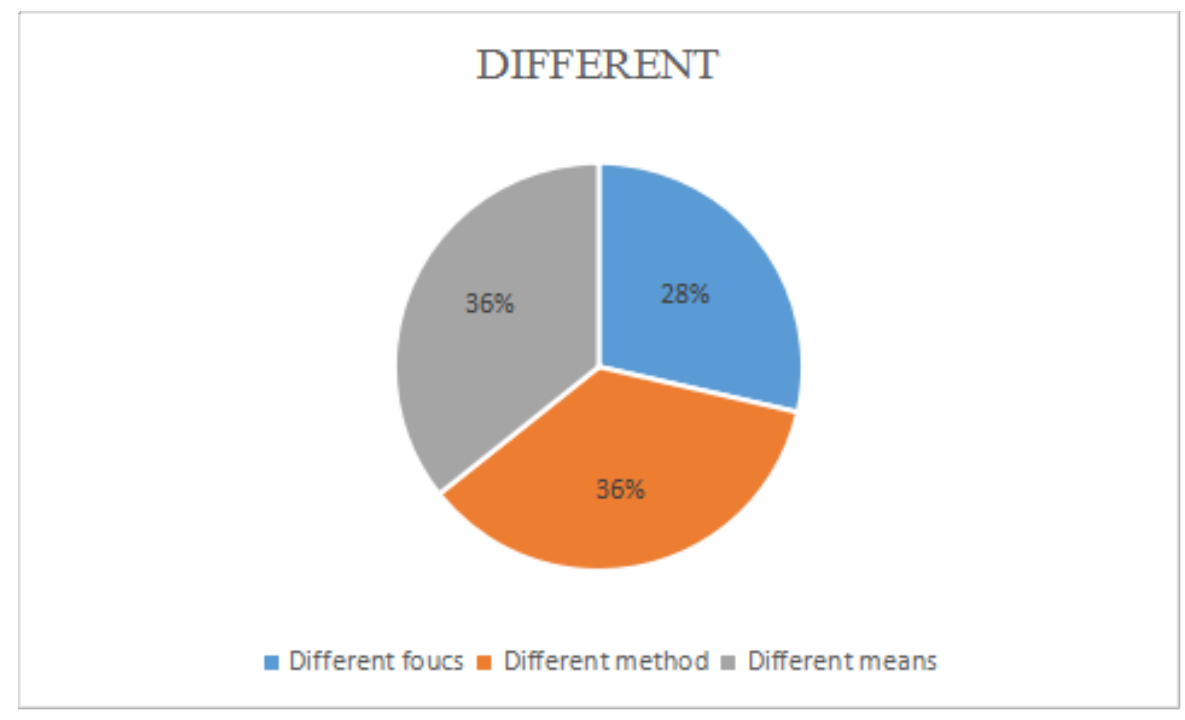

Fig.2

After eliminating four invalid questionnaires, we can see through the analysis of the questionnaire that there are 72 percent of people who think the methods and the means are different and 28 percent of people who thought the focus is different in understanding the difference between music education and the thought politics education. By analyzing different majors separately, we can also see that the ratio of the focus is obviously lower than the others. The reason for this phenomenon is that the students' understanding of music education is not profound.

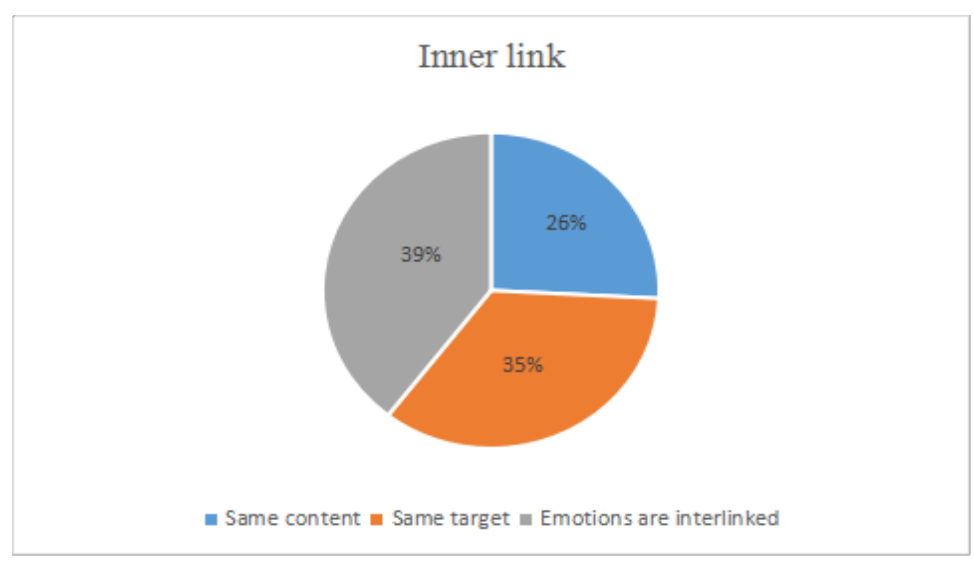

Fig.3

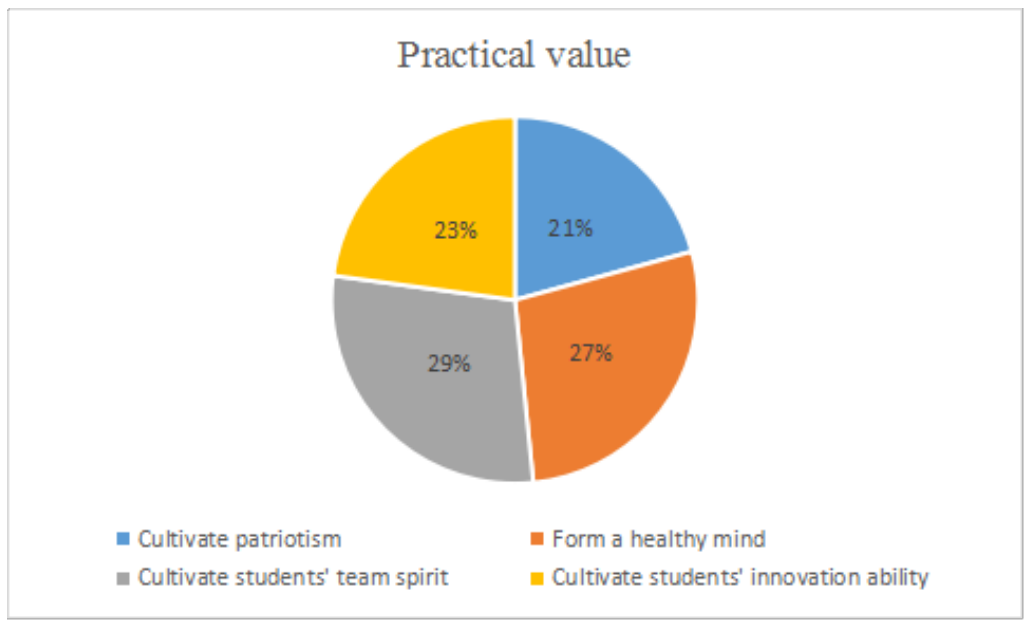

Fig.4

Through the analysis of the pie chart, we can see that the students have basically the same understanding of the inner connection between music education and the ideological and political 
education. Only 26 percent of the students think that their content is in harmony music education and the ideological and political education, which reflects the lack of understanding of the essence of music education. But most students have some thoughts on music education.

By analyzing the pie chart, students think that music education is the best way to cultivate students' team spirit, good choral works need the cooperation of the students. This will enhance the student's team consciousness in the invisible. In the pie chart, there is a small number of people who think that Music education can cultivate patriotism, which may be influenced by popular culture. Nowadays, all music subjects are no longer propagating patriotic thoughts, but sometimes it's a way of expressing your feelings, which makes music education's cultivation of patriotic ideology weaker.

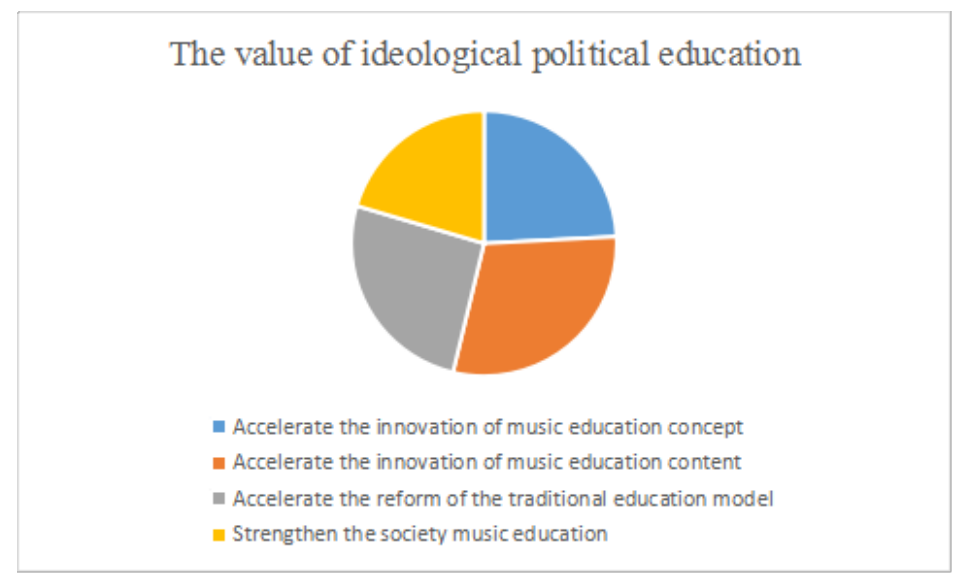

Fig.5

Exploring the value of music education's in the ideological and political education is the focus in this article. This paper discusses from four aspects. In the questionnaire, the idea that we need to accelerate the innovation of music education is the largest proportion. The reason of this phenomenon is that, the traditional music education is still teaching old stuff, something may have not been accepted by the young people, meanwhile, education form is too old-fashioned. The number of people in the study who think that we need to strengthen social music education was the least, because of most people think that the knowledge taught in schools has little to do with social practice.

Through questions 12, 13 and 14, we can conclude that music education's social propaganda effect is reflected in the following three aspects-arouse the patriotism of college students and build good personality, accelerate the innovation of music education content, accelerate the reform of the traditional education model to the ideological and political education in university. Music education's aesthetic value in the ideological and politics education in university is mainly manifested in the role of emotional edify, thought edify and behavior edify.

Music education self-education is mainly reflected in the following aspects in the ideological and politics education in university. Firstly, it can optimize the psychological quality, shaping the perfect personality of college students self-education, improving the ability of self - education of comprehensive quality of college students and cultivating the self-education of independent personality of college students. Secondly, it can improve and perfect the moral education. We can improve students' moral awareness and cultivation through music works, and guide contemporary college students' correct view of life, world view and morality in the training and development of music education. Thirdly, Music is a unique language that can express truth and beauty through different means. We can use singing, instrumental music and appreciation to enhance students' ability of understand, appreciate, understand and create beauty. Fourthly, music education is different from traditional ideological and political education, which can cultivate students' innovative spirit, innovative ideas and innovative thinking in practice, and enhance their consciousness and ability. Excellent music works can create vivid and moving images of art, inspire and infect people, enhance understanding of the culture and history of the motherland, and deepen 
the love of the motherland and the aspirations of the country.

\section{Challenges and Improvement Measures of Music Education in Ideological and Political Education Work in Colleges and Universities}

\subsection{Challenges of music education in ideological and political education work in colleges and universities.}

Thinking is too superficial about the ideological and political education of music education. Most students take music classes because of credit. Meanwhile, influenced by pop music and elegant music, students have a certain aversion to traditional music and elegant music. In teaching practice, the school still focuses on social needs and ignores the cultivation of college students' emotional and ideological and moral qualities.

Music base education level is uneven in university students. The teaching level of music in various regions of Yunnan is unbalanced, especially between urban and rural areas. With the pressure of entrance exam to students, few students can get music education.

The curriculum needs to be further improved. Music education public class in universities generally has a lack of planning, lack of system, and a lack of internal rules and logical connections. Indeed, there are many problems in the courses offered, such as not based on the students' requirements, the existing music quality level and existence the phenomenon of disconnection between theory and practice etc...

\subsection{Improvement measures of music education in ideological and political education work in colleges and universities.}

The role of music education in the ideological and political education depends on the organization and development of campus culture. There are a lot of music education activities in universities, such as a music party for the theme of some moral sentiment - the Lei Feng spirit, create songs that reflect the ideal and spirit of the campus, using a series of new media, such as campus radio station, to spread music with moral charm and using the spread advantage of pop music to push the ideological and political education.

We should pay attention to the integration of teaching content nationality and world. The teaching content of music education must be carefully considered to grasp the mainstream direction of socialism. We should pay attention to the unity of the teaching content in ideological and artistic. This will enable students to feel the beauty of music and get rational satisfaction and moral improvement. By carrying out the music teaching course with national cultural characteristics by combining the local music environment, college students can fully understand the excellent music culture of the Chinese nation, such as the Flowing Stream, Horse Riding Song from Yunnan etc.. Through music education, students can learn about different ethnic characteristics, build national pride and strengthen national cohesion, so as to cultivate the patriotism of youth.

Combine personalized education to establish special club and art group. We should strongly support students', especially students who have personality and vitality after 90s, personal strengths, interests, and motivation need. We can support street dance, music art club, such as pipe band, folk band, and Elegant music into campus. Meanwhile, we can use modern technology such as multimedia and computer to enrich the form and content of the program. Finally, we can build a beautiful campus culture environment, and improve students' thinking, action, knowledge, ability and taste. By penetrating the ideological and political education into all aspects of campus music, we can inspire their pursuit of ideals and love of great motherland with personalized features.

Using special festivals to carry out patriotism education and ideological and moral cultivation. Use various festivals to integrate patriotism and national spirit with music education. such as China's Youth Day, National Day, the founding anniversary of the communist party of China etc., we can carry out deep patriotism education and ideological and moral cultivation to contemporary college students. This can make us more cherish the hard-won life today. In the atmosphere of serious music, such as National Anthem, Chinese Communist Youth League Song, Ode to Our 
Motherland etc., music can let students know the story behind the festival and experience the spirit of it, and make effective emotional education and moral education for students.

Through the combination of music and life, we implemented the impact of the ideological and political education about music. Music comes from life and life is the source of music's art. Good music can show all good thing and the true meaning of life. Students can achieve a perfect mental state with music to infected and education students.

Meanwhile, music teachers should make full use of education conditions. Teachers should constantly strengthen their learning and thinking, and infect students with excellent teaching materials, vivid teaching language and forms. Music teachers should also impart the ideological and political content, ethical moral connotation and music aesthetic at the same time in the teaching process.

\section{References}

[1] Wei Cao. Brief on music education's ideological and political education function [D]. Hebei Normal University, 2011

[2] Aili Li. The function of music education in university students' ideological and political education [J]. School party building and thinking education, 2010(17):39-40.

[3] Ling Zhao. The function of music education in the education of thought [J]. Journal of education school of administration in liaoning province, 2009, 26(02):128.

[4] Yongfei Xie. The special function of music education in the modern college students' ideological and political education [J]. Yellow River of the Song, 2014(15):92-93.

[5] Rongrong Zhang, The function of music education in university students' ideological and political education[D]. Hunan Normal University, 2011. 